\title{
Thermal Stresses Analysis and Optimized TTP Processes to Achieved CNT-Based Diaphragm for Thin Panel Speakers
}

\author{
Feng-Min Lai and Chang-Yi Peng \\ Department of Materials Science and Engineering, Da-Yeh University, Changhua 51591, Taiwan \\ Correspondence should be addressed to Feng-Min Lai; fengmin@mail.dyu.edu.tw
}

Received 6 March 2016; Accepted 7 June 2016

Academic Editor: Ying-Lung D. Ho

Copyright ( 2016 F.-M. Lai and C.-Y. Peng. This is an open access article distributed under the Creative Commons Attribution License, which permits unrestricted use, distribution, and reproduction in any medium, provided the original work is properly cited.

Industrial companies popularly used the powder coating, classing, and thermal transfer printing (TTP) technique to avoid oxidation on the metallic surface and stiffened speaker diaphragm. This study developed a TTP technique to fabricate a carbon nanotubes (CNTs) stiffened speaker diaphragm for thin panel speaker. The self-developed TTP stiffening technique did not require a high curing temperature that decreased the mechanical property of CNTs. In addition to increasing the stiffness of diaphragm substrate, this technique alleviated the middle and high frequency attenuation associated with the smoothing sound pressure curve of thin panel speaker. The advantage of TTP technique is less harmful to the ecology, but it causes thermal residual stresses and some unstable connections between printed plates. Thus, this study used the numerical analysis software (ANSYS) to analyze the stress and thermal of work piece which have not delaminated problems in transfer interface. The Taguchi quality engineering method was applied to identify the optimal manufacturing parameters. Finally, the optimal manufacturing parameters were employed to fabricate a CNT-based diaphragm, which was then assembled onto a speaker. The result indicated that the CNT-based diaphragm improved the sound pressure curve smoothness of the speaker, which produced a minimum high frequency dip difference $(\Delta \mathrm{dB})$ value.

\section{Introduction}

The thermal transfer printing (TTP) technique is coating materials to combine on the metallic surface in high thermal environment. This study explores thermal stresses analysis of coating, to make the coating boundary have a good combination, especially. The research of thermal conduction in composite materials is various in the recent years. Ozisik indicated that the composite structures are formed by two or more plates; the connection between any two plates tends to have the problem of thermal resistance [1]. Previous studies have reported that the magnitude and distribution of thermal residual stress can be adjusted by selecting the appropriate material combination and controlling the compositional gradient. Shaw used the multilayer composite plates with different materials to form the elastic module and coating them on different plates and found that different coating thicknesses will influence the characteristics of thermal residual stresses [2]. Özel et al. used the finite elèment method (FEM) to simulate various ceramic materials, which are analyzed by their thermal stresses under the very high temperature [3].

Current technological products, including speakers, are mostly lightweight. Speakers have become an integral part of people's everyday life and are prevalently applied in a variety of products such as television, computers, tablet computers, and mobile phones. To fulfill market demands and customer needs for thinner panel speakers with excellent sound quality, problems concerning middle and high frequency attenuation in thin panel speakers must be resolved. The diaphragm in thin panel speaker is the key component of a speaker. The mechanical property of a diaphragm directly influences crucial acoustic characteristics of the speaker (including the sound pressure level (SPL) and frequency range).

Typically, the major material of the diaphragm is coarse paper. However, the lack of stiffness produces unclear sound at middle and high frequency. Therefore, polyethylene naphthalate (PEN) pasted on coarse paper or Al foil pasted on form materials has been studied to enhance the stiffness. However, 
poor adhesion and overweight problem occur and limit their application. It is reported that using CNTs as an additive can enhance the mechanical property of resin [4-6]. Compared with regular polymer, CNTs have lower expansion coefficient, which reduces the residual stress in laminated polymer composites. In addition, CNTs have favorable strength and stiffness and are capable of changing material properties such as electrical and thermal conductivity. However, past studies also have observed that mixing high-concentration CNTs with epoxy lowers the mechanical strength of the epoxy, which is primarily attributable to the aggregation of the CNTs and the formation of hollow pores in the epoxy $[7,8]$. Regardless, the composite coating containing CNTs and epoxy has not been studied for using as the diaphragm in thin panel speaker.

In this study, we self-developed a TTP technique to prepare the diaphragm in thin panel speaker. TTP is a manufacture through which coatings are bonded to the surface of a transfer material at temperature from $80^{\circ} \mathrm{C}$ to $120^{\circ} \mathrm{C}$ [9]. The composite paste of CNTs and epoxy was first rollerpressed onto a polyethylene naphthalate (PEN) substrate to reinforce the PEN, after which the backside of the PEN was coated with hot melt adhesive (HMA). The fabricated TTP paper (CNTs+epoxy/PEN/HMA) was cut into adequate size and shape. Next, a TTP machine was used to locally or fully press TTP paper onto a coarse paper to manufacture a stiffened speaker diaphragm. Bian and Zhao reported that Young's moduli of CNTs decrease when the temperature of the environment exceeds $200^{\circ} \mathrm{C}$ [10]. In our study, the proposed TTP stiffening technique does not require a high curing temperature that decreases the mechanical property of CNTs, and the TTP technique can stiffen a localized area on a diaphragm substrate, thus increasing diaphragm stiffness without markedly raising diaphragm weight; hence, the inherent strength of CNTs was preserved. The resulting CNT-based diaphragm exhibited increased stiffness, which improved the bandwidth and sound quality of the speaker, thereby markedly improving the overall smoothness of the sound curve. Simultaneously, the weight was reduced and the adhesion was also improved while using the CNTbased diaphragm. Besides, in this study, the Taguchi quality engineering method $[11,12]$ was used to minimize the number of experimental trials. The paper is relationship among the manufacturing parameters including stiffening pattern, coating direction, transfer area, and transfer temperature of CNT-based diaphragm which have also been therefore investigated.

\section{Analysis and Experimental Procedure}

2.1. Analysis on ANSYS. The finite element method (FEM) is used in this study by the assistance of ANSYS PLANE42 element (Figure 1). PLANE-42 element is used for 2D modeling for solid structures [13]. The element can be used either as a plane element or as an axisymmetric element. The element has plasticity, creep, swelling, stress stiffening, large deflection, and large strain capabilities. The following steps are used to construct our model.

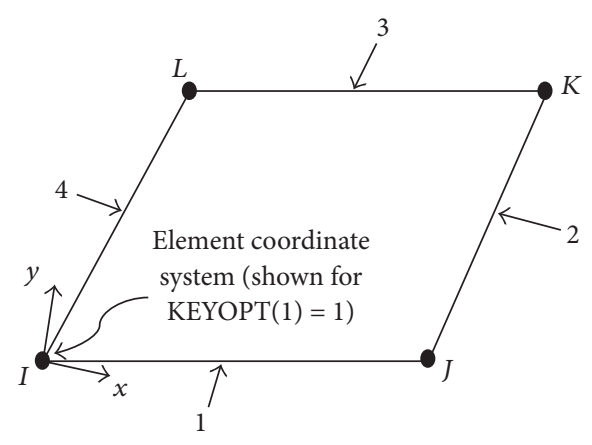

Figure 1: PLANE-42 element of ANSYS [13].

Step 1. Build the solid structure and the finite element model.

Step 2. Apply loads and obtain the solution.

Step 3. Review the stresses.

Step 4. Perform a design for optimization analysis.

Eventually, PLANE-42 element is applying the 2D module to approximate the $3 \mathrm{D}$ module. It can effectively reduce the computation time and accurately analyze the stress values. The element is defined by four nodes having two degrees of freedom at each node and is translated in the nodal $x$ and $y$ directions. We can use these data to compute the shift, stress, and angles.

This study assumes that the stress is maximized along $x$-axis. First the element type and the property of material are defined to establish the finite element model. Second, the necessary boundary conditions are given and the stresses are resolved. Third, $\sigma_{x}$ is maximized for the nodes, which are generated along the interface of the metallic material (base) and the coating material (coating). Finally, the study used ANSYS to analyzed the stress results for CNT-based diaphragm.

2.2. Fabrication of TTP Paper and CNT-Based Diaphragm. In this study, a PEN membrane was used as the substrate for fabricating TTP paper. The front and back of the PEN were, respectively, coated with CNT/epoxy and HMA to form the TTP paper. The fabricated TTP paper was then thermally transferred and printed onto a coarse paper to form a diaphragm. Subsequently, the effect of diaphragm fabrication on sound pressure curve smoothness was investigated, and Taguchi quality engineering method was applied to identify the optimal manufacturing parameters.

A PEN membrane was used as the substrate for fabricating TTP paper. We first mixed 2 3 wt\% CNTs (CF182C, Advanced Nanopower Inc.) and epoxy (P859-1, Hong Guan R\&D Co.) as the CNTs/epoxy composite paste. In fact, the CNTs with a density of $1.3 \sim 1.4 \mathrm{~g} / \mathrm{cm}^{3}$ (similar to the cotton) are very fluffy and its volume is quite large. Although we have also mixed $4 \sim 5 \mathrm{wt} \%$ CNTs and epoxy, the experiment result indicates that it requires a much longer mixing time, and the mixture has a high viscosity. This would lead to a 


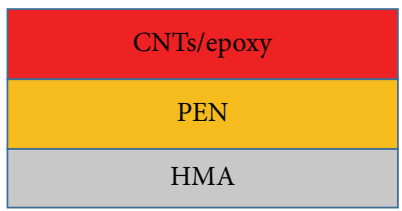

(a)

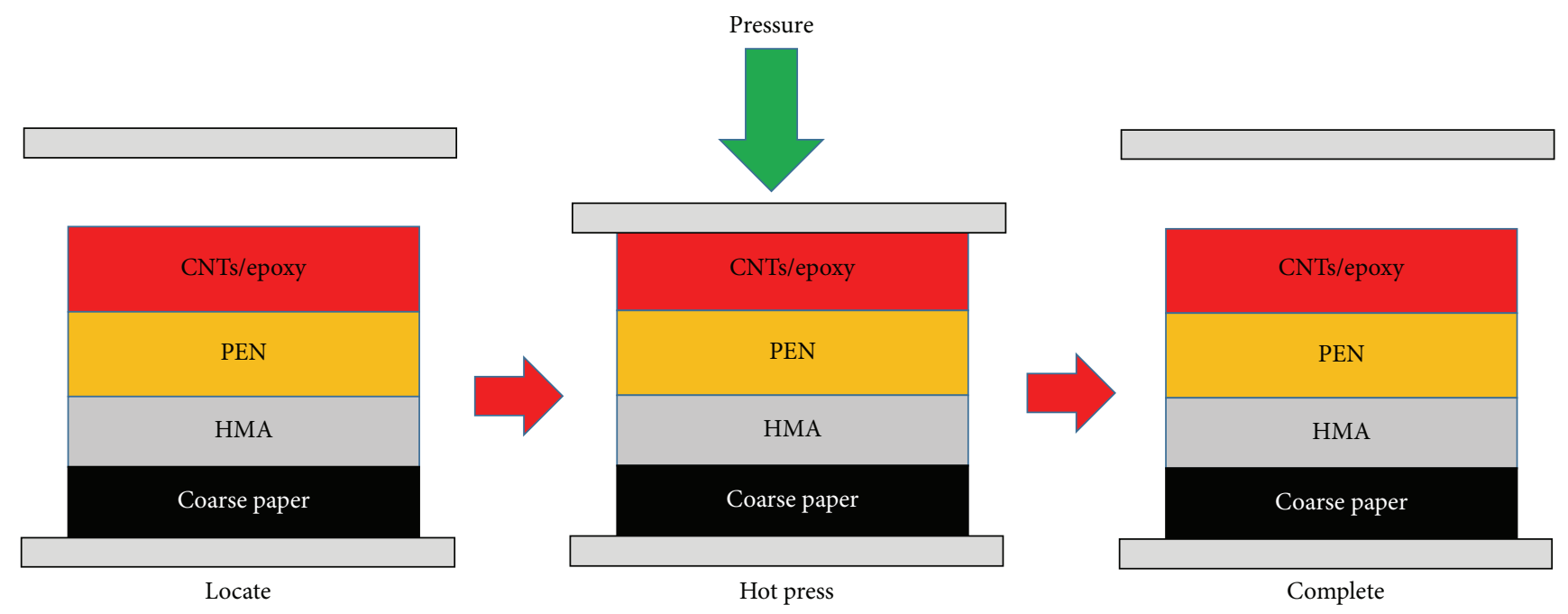

(b)

FIgURE 2: Schematic CNT-based diagram of the (a) TTP paper and (b) TTP processes.

nonuniform surface of the TTP paper. As shown in Figure ??, the TTP paper was fabricated by coating the front side of a PEN membrane with CNTs/epoxy paste and then drying it in an oven at $120^{\circ} \mathrm{C}$ for $15 \mathrm{~min}$. After the CNTs/epoxy coating layer was dried, the backside of PEN was coated with HMA and was dried again in the oven at $80^{\circ} \mathrm{C}$ for $10 \mathrm{~min}$ to obtain a TTP paper. The CNTs/epoxy coating was used to adjust the thickness of TTP paper; in addition, manually roller-pressing the CNTs/epoxy coating onto the TTP paper enabled evenly spreading the coating onto the material surface.

After the fabrication of TTP paper, a TTP process was used to thermally transfer and print the TTP paper onto coarse paper to form a CNT-based diaphragm at an elevated temperature. In this study, as shown in Figure ??, the resulting TTP paper was first stacked onto the coarse paper diaphragm and then subjected to a TTP process in a TTP machine. The following steps of TTP process were illustrated in Figure ??. After pressing to $0.2 \mathrm{~kg} / \mathrm{cm}^{2}$ and heating at $80 \sim$ $120^{\circ} \mathrm{C}$ for $10 \mathrm{~min}$, the fabrication of CNT-based diaphragm was complete. This study also adopted cold cathode field emission scanning electron microscope (FE-SEM; JEOL JSM$740 \mathrm{~F}$, Japan) to observe the cross sections of the CNT-based diaphragm.

2.3. Material Properties for Test Specimens. To obtain the properties and strengths of the coarse paper, TTP paper, and CNT-based diaphragm, three types of tensile specimen geometry will be employed. The test specimen dimensions are $12.5 \mathrm{~mm} \times 100 \mathrm{~mm}$. The material properties of laminated composite face sheets and foam core where determined from experiments conducted in accordance with the relevant ASTM (D3039-79 and D3518-76) standards [14]. The specimens should be mounted and tested in a properly aligned and calibrated INSTRON-1332 test machine. Wedge action friction grips of hydraulic grips will be used. Set the crosshead rate at about $10 \mathrm{~mm} / \mathrm{min}$. The strains and load readings may be recorded continuously or at discrete load intervals. If the discrete data are taken, a sufficient number of data points must be recorded in order to reproduce the stress-strain relation. At least 25 data points are needed in the linear response region. Monitor all specimens to failure and then determine the ultimate strengths and strains. Plot the data for reduction. Establish the Young's modulus and Poisson's ratio by a least square fit of the linear region. For finding the mechanical properties and ultimate strengths (strains), some specimens are tested statically to failure. The stress-strain response of tensile coupon is monitored with electrical resistance strain gauge in order to find the intrinsic mechanical properties of the coarse paper, TTP paper, and CNT-based diaphragm. The material properties to be measured include (i) Young's modulus, (ii) Poisson's ratio, (iii) ultimate tensile stress (failure strength).

2.4. Panel Speaker Assembly. Figure 3(a) shows the SolidWorks explosion diagram of the panel speaker. After various speaker components were prepared and ready for assembly, the fabricated CNT-based diaphragm was adhered to the speaker surround, which was then assembled to the upper frame as shown in Figure 3(b). The surround material 


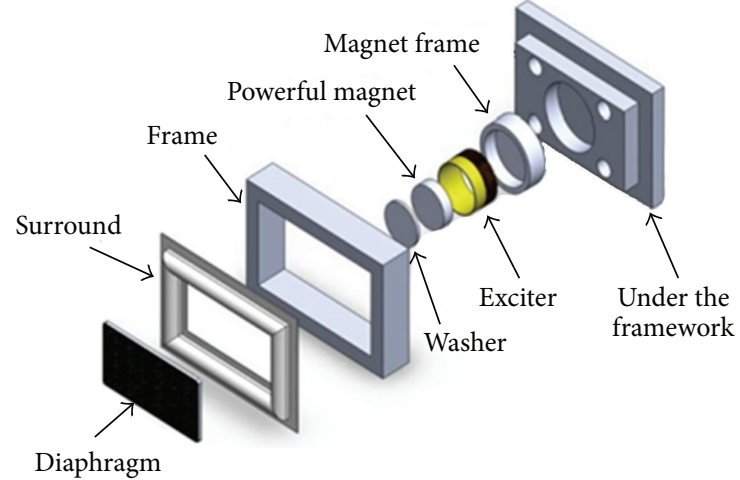

(a)
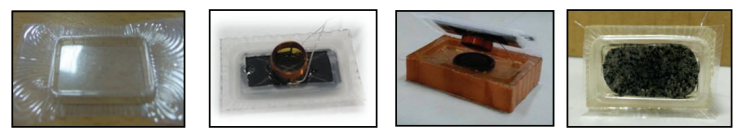

(b)

FIGURE 3: (a) SolidWorks explosion diagram of the thin panel speaker; (b) thin panel speaker assembly processes.

selected for our panel speaker was polyurethane (PU) with the actual specification which is $30 \times 20 \times 10 \mathrm{~mm}$. PU was placed into a surround mold and heat pressed in an oven to form the speaker surround, which was then attached to the diaphragm and voice coil. Subsequently, the vibration exciter (voice coil) was attached at $90^{\circ}$ perpendiculars to the diaphragm. A shown in Figures 3(a) and 3(b), the exciter was placed between the magnet and the magnet frame. The magnets were placed above the washer to increase the magnetic flux. The speaker gives sound through the diaphragm vibration that pushed by the voice coil. Most importantly, the vibration exciter (voice coil) must be attached to the central area of the diaphragm. Otherwise, sound distortion is easily incurred. Once all the steps have been completed, the adhesives were allowed to solidify for a day, after which the sound pressure curve of the speaker can be measured.

2.5. Sound Pressure Curve Measurement and Analysis. To avoid influencing the measurement results, sound pressure curve must be measured in an anechoic chamber insulated from external sources of noise; acoustical measurement system and CLIO software analysis were employed in measuring the sound pressure curve. In the CLIO software, the number of points, bandwidth, and voltage were defined. The measured bandwidth was $20 \mathrm{~Hz} 20 \mathrm{kHz}$ audible to the human ear and was measured at a distance of $10 \mathrm{~cm}$ from the selfdeveloped panel speaker. Subsequently, after the input voltage of the speaker was configured, the sound pressure curve and data were measured. In the sound pressure curve, the value difference $(\Delta \mathrm{dB})$ between curve valley and sound pressure level (SPL) at $12 \sim 18 \mathrm{kHz}$, high frequency dip difference value $(\Delta \mathrm{dB})$, was used to identify the quality of the sound. A minimum high frequency dip difference value $(\Delta \mathrm{dB})$ gives a smooth sound pressure curve in the high frequency region and a better sound quality.
2.6. Taguchi Quality Engineering. Because stiffening the entire diaphragm may influence the overall sensitivity of the speaker, we attempted to circumvent this problem by performing optimization analysis using the Taguchi method. Through the Taguchi approach, the optimal product design objective or process can be determined to facilitate mitigating the effects of confounding factors [11, 12]. This study investigated the relationship among the manufacturing parameters of CNT-based diaphragm (stiffening pattern, coating layers, transfer area, and heat press temperature), and the Taguchi equations representing the smaller-the-better (see (1)) characteristics are shown as follows:

$$
\mathrm{S} / \mathrm{N}=-10 \log _{10} \frac{\sum_{k=1}^{n} Y^{2} i}{n} .
$$

The selected manufacturing parameters of CNT-based diaphragm were aimed at having a minimum high frequency dip difference value $(\Delta \mathrm{dB})$ in the sound pressure curve of a speaker, subsequently smoothing the sound pressure curve in the high frequency region. Figures 4 and 5 present the parameters obtained from the Taguchi method. Figures 4(a) and 4(b) show the top and side view of the transfer area of the TTP paper on coarse paper, respectively. Figure 5 illustrates the stiffening patterns on the TTP paper and the coating direction of 1 or 2 coating layers. Furthermore, the analysis of variance (ANOVA) was also used to find the dominant influence factors.

\section{Results and Discussion}

3.1. Comparison of ANSYS and Related Papers for Numerical Example. The manufacturing parameters of coating materials on a flat plate are the thickness of coating and the order of plates. We compared our ANSYS results with other similar researches. After that, we actually used the ANSYS model for simulation. The material properties of metals and coating materials are shown Table 1 .

Shaw [2] indicated that the influencing factors of our analysis are the composition gradient, the elastic module, number of layers, thermal expansion coefficients, and so forth. Shaw used functionally graded materials (FGM) and multilayer composite material on thermal coating and analyzed the thermal residual stress. Since our study was similar to Shaw's results, we compared three materials of metal and ceramic with Shaw's results in Table 2.

Furthermore, Özel et al. [3] coated the advanced ceramic on the metallic plate and minimized the stress as his goal. We also use the stress objective proposed by Özel et al. as our programming goal in this study. And different coating materials, $\mathrm{Si}_{3} \mathrm{~N}_{4}, \mathrm{Al}_{2} \mathrm{O}_{3}$, and $\mathrm{TiC}$ are coated on the $\mathrm{W}$ metal plate by ANSYS methods so as to compare the thermal stresses with Özel et al.s results in Table 3. The fluctuation between the analytic results from ANSYS method and published practical results fluctuated from $1.42 \%$ to $7.66 \%$ with a summarized average $4.31 \%$. Therefore, the paper used the ANSYS method into coarse paper and TTP paper interface shear stress problem. Finally, we compare our ANSYS model 
TABLE 1: Material properties of metals and coating materials.

\begin{tabular}{|c|c|c|c|c|}
\hline \multirow[b]{2}{*}{ Materials } & \multicolumn{4}{|c|}{ Properties } \\
\hline & $\begin{array}{l}\text { Young's modulus } E \\
\qquad(\mathrm{GPa})\end{array}$ & Poisson's ratio $v$ & $\begin{array}{l}\text { Thermal conductivity, } K \\
\qquad\left(\mathrm{~W} / \mathrm{m}^{\circ} \mathrm{C}\right)\end{array}$ & $\begin{array}{c}\text { Coefficient of thermal } \\
\text { expansion }(\mathrm{CTE}), \alpha \\
\left(1 /{ }^{\circ} \mathrm{C}\right)\end{array}$ \\
\hline $\mathrm{Al}$ & 70 & 0.33 & 34 & $2.3 \times 10^{-5}$ \\
\hline $\mathrm{W}$ & 410 & 0.28 & 29 & $4.5 \times 10^{-6}$ \\
\hline Diamond & 1050 & 0.20 & 2 & $1.75 \times 10^{-6}$ \\
\hline $\mathrm{Si}_{3} \mathrm{~N}_{4}$ & 230 & 0.26 & 28 & $3.5 \times 10^{-6}$ \\
\hline $\mathrm{Al}_{2} \mathrm{O}_{3}$ & 340 & 0.23 & 24 & $8.1 \times 10^{-6}$ \\
\hline $\mathrm{TiC}$ & 340 & 0.19 & 27 & $7.1 \times 10^{-6}$ \\
\hline $\mathrm{NiAl}$ & 103 & 0.17 & 5.3 & $14.6 \times 10^{-6}$ \\
\hline
\end{tabular}
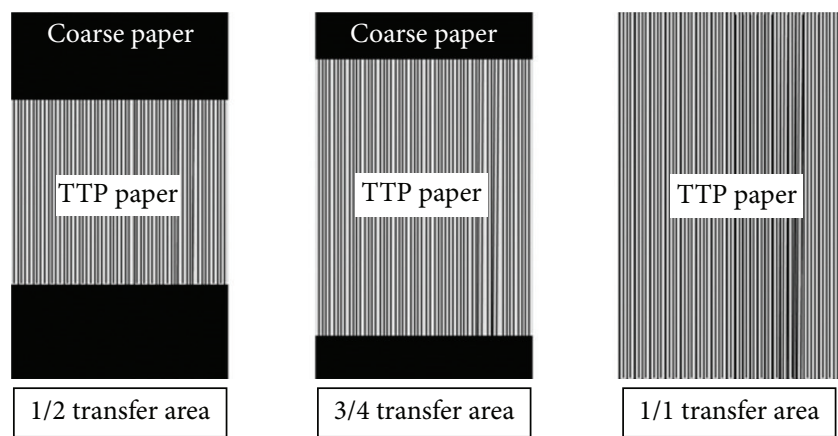

(a)
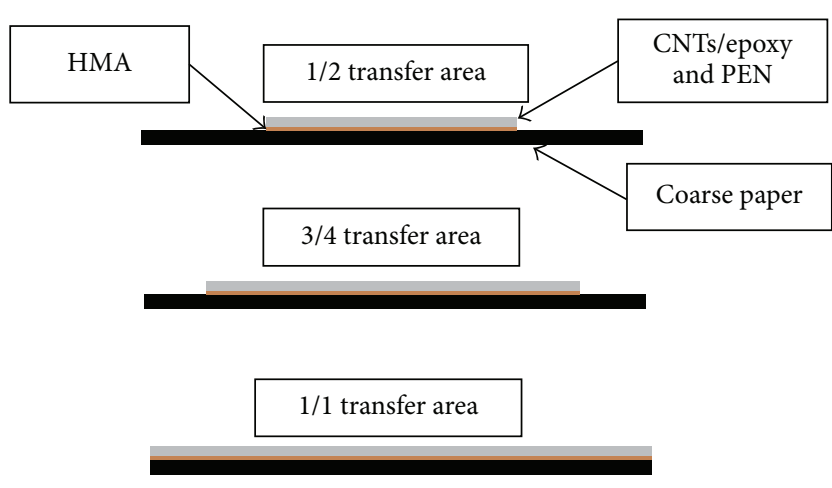

(b)

FIgURE 4: (a) Top view of three types of transfer area; (b) side view of three types of transfer area.

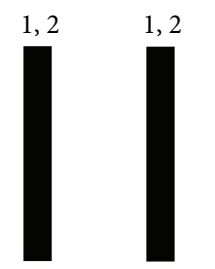

Unidirectional

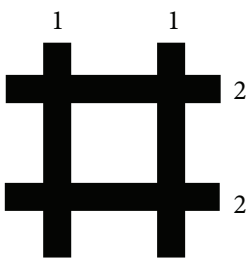

$90^{\circ}$ cross

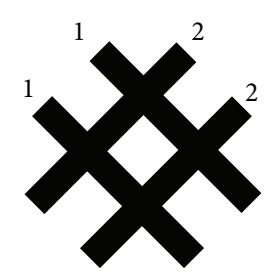

$45^{\circ}$ angle
Figure 5: Three types of stiffening patterns of the TTP paper. Numbers present the coating direction of patterns containing 1 or 2 coating layers.
TABLE 2: Comparison of Shaw's results and ANSYS.

\begin{tabular}{lccc}
\hline $\begin{array}{l}\text { Material } \\
\text { properties }\end{array}$ & $\begin{array}{c}\text { Shaw [2] } \\
\sigma_{x}\left(c_{g}\right)\end{array}$ & $\begin{array}{c}\text { ANSYS } \\
\text { method } \\
\sigma_{x}\left(c_{d}\right)\end{array}$ & $\begin{array}{c}\text { Differential } \\
\left|\left(c_{g}-c_{d}\right) / c_{g}\right| \times 100 \%\end{array}$ \\
\hline I $(\mathrm{MPa})$ & 1745 & 1951.3 & $11.82 \%$ \\
II $(\mathrm{MPa})$ & 1715 & 1749.1 & $1.98 \%$ \\
III $(\mathrm{MPa})$ & 996.5 & 914.4 & $8.23 \%$ \\
\hline
\end{tabular}

TABLE 3: Compare the stresses' decrease progressively with Özel et al.'s results and ANSYS method.

\begin{tabular}{lccc}
\hline $\begin{array}{l}\text { Material } \\
\text { properties }\end{array}$ & $\begin{array}{c}\text { Özel et al. } \\
{[3]}\end{array}$ & $\begin{array}{c}\text { ANSYS } \\
\text { method } \\
\sigma_{x}\left(c_{g}\right)\end{array}$ & $\begin{array}{c}\sigma_{x}\left(c_{d}\right) \\
\left|\left(c_{g}-c_{d}\right) / c_{g}\right| \times 100 \%\end{array}$ \\
\hline $\mathrm{W}+\mathrm{Si}_{3} \mathrm{~N}_{4}$ & $-92 \%$ & $-95.56 \%$ & $3.86 \%$ \\
$\mathrm{~W}+\mathrm{Al}_{2} \mathrm{O}_{3}$ & $-136 \%$ & $-125.58 \%$ & $7.66 \%$ \\
$\mathrm{~W}+\mathrm{TiC}$ & $-121 \%$ & $-119.27 \%$ & $1.42 \%$ \\
\hline
\end{tabular}

TABLE 4: Comparing results with Han and Sun's study and ANSYS.

\begin{tabular}{lccc}
\hline \multirow{3}{*}{ Stress } & \multicolumn{3}{c}{ Methods } \\
& Han and & ANSYS & Differential \\
& Sun [15] & method & $\left|\left(c_{g}-c_{d}\right) / c_{g}\right| \times 100 \%$ \\
\hline$\sigma_{x}(\mathrm{MPa})$ & 37 & 41.68 & $12.64 \%$ \\
\hline
\end{tabular}

with Han and Sun's study in Table 4. Han and Sun [15] used the glass and alumni as his test base.

According to the aforementioned comparisons, we can say that our ANSYS model is adequate to approximate the actual thermal coating process. We also believe that the ANSYS model is able to simulate the actual behavior of TTP technology.

3.2. ANSYS Analyzed the Stress Results for CNT-Based Diaphragm. The specimens are used by INSTRON-1332 test machine to obtain Young's modulus and strengths of the coarse paper, TTP paper, and CNT-based diaphragm which are shown in Table 5. The study compared CNT-based 
TABLE 5: Properties of coarse paper, TTP paper, and CNT-based diaphragm.

\begin{tabular}{|c|c|c|c|c|c|}
\hline \multirow[b]{2}{*}{ Materials } & \multicolumn{5}{|c|}{ Properties } \\
\hline & Thicknesses (mm) & $\begin{array}{l}\text { Young's modulus } E \\
\text { (GPa) }\end{array}$ & $\begin{array}{l}\text { Failure Strength } \\
(\mathrm{MPa})\end{array}$ & Poisson's ratio $v$ & CTE, $\alpha\left(1 /{ }^{\circ} \mathrm{C}\right)$ \\
\hline Coarse paper $\left(C_{g}\right)$ & 0.210 & 2.14 & 32.51 & 0.28 & $2.3 \times 10^{-6}$ \\
\hline TTP Paper & 0.027 & 2.71 & 48.82 & 0.33 & $25.1 \times 10^{-6}$ \\
\hline $\begin{array}{l}\text { CNT-based diaphragm } \\
\left(C_{d}\right)\end{array}$ & 0.237 & 2.58 & 45.12 & 0.31 & - \\
\hline $\begin{array}{l}\text { Differential } \\
\left|\left(c_{g}-c_{d}\right) / c_{g}\right| \times 100 \%\end{array}$ & - & $20.56 \%$ & $26.48 \%$ & - & - \\
\hline
\end{tabular}

TABLE 6: Mechanical properties of CNT-based diaphragm with different TTP curing temperature.

\begin{tabular}{lccc}
\hline Temperature & $\begin{array}{c}\text { Properties } \\
\text { Thicknesses } \\
(\mathrm{mm})\end{array}$ & $\begin{array}{c}\text { Young's } \\
\text { modulus } \\
(\mathrm{GPa})\end{array}$ & $\begin{array}{c}\text { Failure strength } \\
(\mathrm{MPa})\end{array}$ \\
\hline $100^{\circ} \mathrm{C}$ & 0.245 & 2.23 & 35.51 \\
$120^{\circ} \mathrm{C}$ & 0.237 & 2.58 & 41.12 \\
$130^{\circ} \mathrm{C}$ & 0.237 & 2.59 & 41.08 \\
$140^{\circ} \mathrm{C}$ & 0.237 & 2.57 & 41.10 \\
\hline
\end{tabular}

TABLE 7: Mechanical properties of TTP papers with different CNTs wt $\%$.

\begin{tabular}{lccc}
\hline Wt\% & $\begin{array}{c}\text { Properties } \\
\text { Thicknesses } \\
(\mathrm{mm})\end{array}$ & $\begin{array}{c}\text { Young's } \\
\text { modulus } \\
(\mathrm{GPa})\end{array}$ & $\begin{array}{c}\text { Failure strength } \\
(\mathrm{MPa})\end{array}$ \\
\hline $3 \mathrm{wt} \%$ & 0.027 & 2.71 & 48.82 \\
$5 \mathrm{wt} \%$ & 0.032 & 2.68 & 48.75 \\
\hline
\end{tabular}

diaphragm with coarse paper mechanical properties which is increased $20.56 \%$ with Young's modulus results in Table 5. This study developed a TTP technique to fabricate a CNTs stiffened coarse paper which could be manufactured speaker diaphragm.

The thermosetting resins with a curing temperature of $120^{\circ} \mathrm{C}$ were used in this study. After curing at $120^{\circ} \mathrm{C}$, a network structure was formed in the resin by intermolecular crosslinking. Moreover, the resin was not softened even though the reheating treatment was performed. Therefore, selfdeveloped TTP stiffening technique does not require high curing temperature. The experiment results on mechanical properties of CNT-based diaphragm with different TTP curing temperature are shown in Table 6. It reveals that the CNTbased diaphragm with the $120^{\circ} \mathrm{C}$ curing temperature has good mechanical properties. Additionally, the mechanical properties of TTP papers with different CNTs wt\% (3wt\% and $5 \mathrm{wt} \%$ ) are summarized in Table 7 . It is obvious that these two TTP papers have almost the same mechanical properties. Therefore, we used $3 \mathrm{wt} \% \mathrm{CNT} /$ epoxy coating onto the TTP papers which could reduce the cost and has the uniform coating surface.

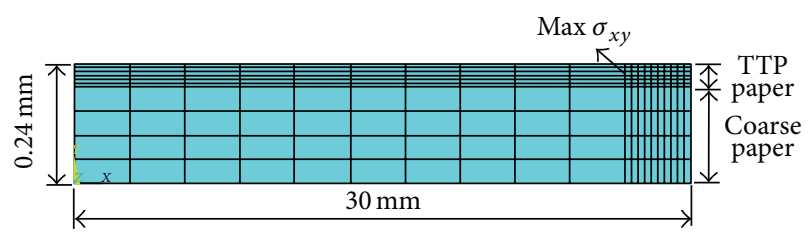

FIGURE 6: Module of finite element method (FEM) with structure of CNT-based diaphragm.

We also believe that the ANSYS model (see Figure 6) is able to simulate the actual behavior of CNT-based diaphragm (model's dimension is $30 \times 0.24 \mathrm{~mm}$ ) with TTP temperature at $80^{\circ} \mathrm{C}$, and our simulated results are available in Table 8. The study compared shear stress result with coarse paper and TTP failure strength; the shear stress is less than 166.6 $299.8 \%$ of the breaking strength of the coarse paper and TTP material which is safe in transfer interface. This study used the numerical analysis software (ANSYS) to analyzed the stress and thermal of work piece which have not been delaminated problems in transfer interface. The materials with the higher failure strength could allow the shear stress at high temperatures, which did not produce the peeling problem in the transfer interface.

3.3. Microscopic Structure of CNT-Based Diaphragm. Figure 7 presents the sectional images of the CNT-based diaphragm. For a conventional speaker diaphragm fabrication, a PEN pasted on the coarse paper directly. By using the TTP process, as shown in Figures 7(a) and 7(b), the hot melt layer diffuses into the coarse paper and gives an enhanced adhesion. Figure 7(b) shows the enlarged photo of Figure $7(\mathrm{a})$. On the images, arrows represent the material structure in various regions of the diaphragm. It was observed that CNTs/epoxy coating was evenly applied onto the diaphragm. The coated coarse paper presented more grooves and deeper grooves of uneven depth than the coated PEN paper did, primarily because the coarse paper contained a mixture of fibers. In addition, the FE-SEM images revealed that the CNTs/epoxy coatings on the coarse paper and PEN side of the paper were evenly distributed on the coating material, indicating that the coating was evenly and favorably dispersed. The sectional FE-SEM images show that the TTP paper is tightly bound to the coarse paper substrate, exhibiting an even thickness approximating $269.5 \mu \mathrm{m}$. 
TABLE 8: Comparing results with ANSYS method and material failure strength.

\begin{tabular}{lccccc}
\hline Shear stress & $\begin{array}{c}\text { ANSYS } \\
\text { analysis result }\left(C_{A}\right)\end{array}$ & $\begin{array}{c}\text { Coarse paper failure } \\
\text { strength }\left(C_{c}\right)\end{array}$ & $\begin{array}{c}\text { Methods } \\
\text { TTP paper failure } \\
\text { strength }\left(C_{T}\right)\end{array}$ & $\begin{array}{c}\text { Differential } \\
\left|\left(c_{C}-c_{A}\right) / c_{A}\right| \times 100 \%\end{array}$ & $\begin{array}{c}\text { Differential } \\
\left|\left(c_{T}-c_{A}\right) / c_{A}\right| \times 100 \%\end{array}$ \\
\hline$\sigma_{x y}(\mathrm{MPa})$ & 12.2 & 32.51 & 48.82 & $166.3 \%$ & $299.8 \%$ \\
\hline
\end{tabular}

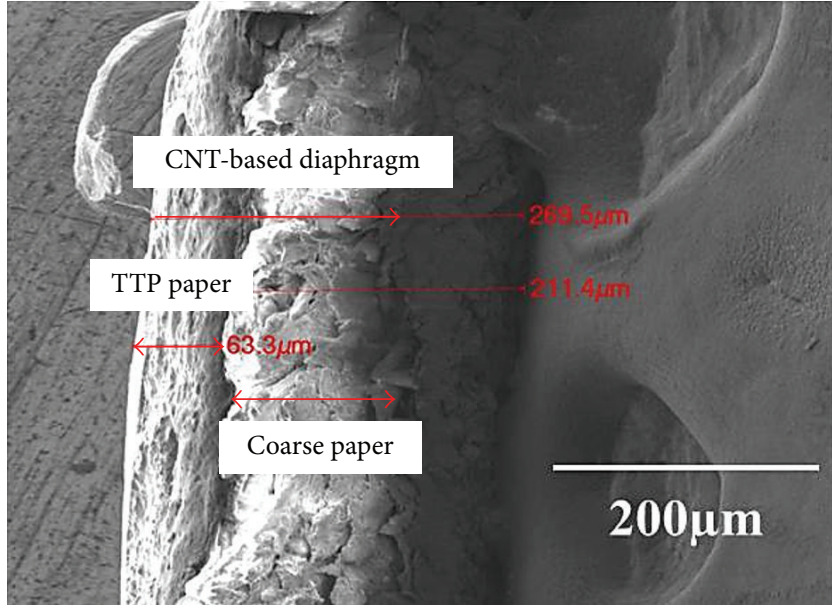

(a)

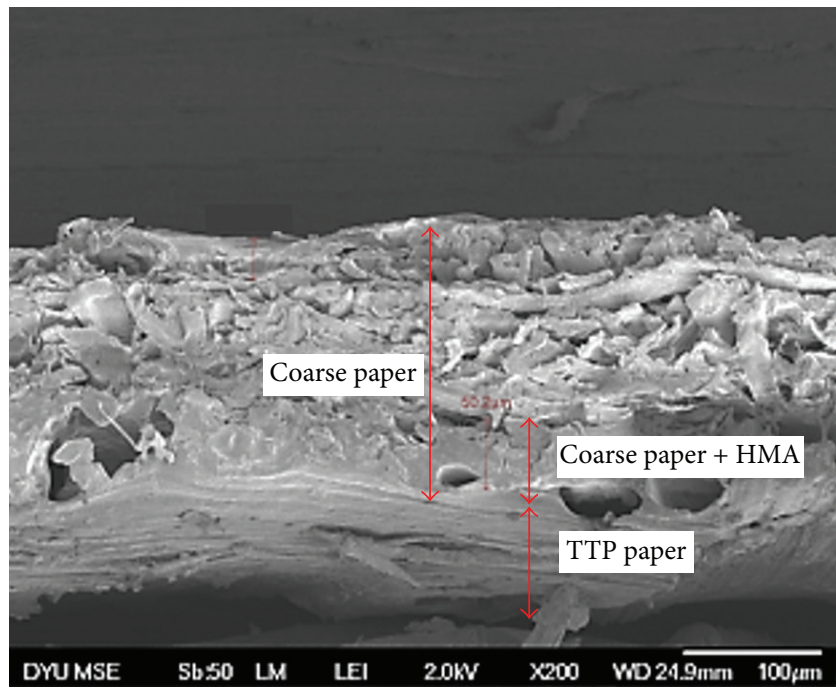

(b)

FIGURE 7: FE-SEM sectional images of (a) the self-developed speaker diaphragm. (b) is the enlarged photo of (a).

\subsection{Taguchi Quality Engineering: Optimal High Frequency Dip} Difference Value $(\Delta d B)$. This high frequency dip difference value primarily influences the smoothness and bandwidth of the curve; a small valley difference indicates large sound range, which increases the clarity of the speaker's midfrequency and high frequency sounds. Therefore, the minimal high frequency dip difference value is desirable. As shown in Table 9, the Taguchi quality engineering method was used to minimize the number of experimental trials, and the applicable orthogonal array was selected according to the
TABle 9: Taguchi-selected factors.

\begin{tabular}{lcccc}
\hline & Factors & \multicolumn{3}{c}{ Level } \\
& & 1 & 2 & 3 \\
\hline$A$ & Transfer area & $1 / 2$ & $3 / 4$ & $1 / 1$ \\
$B$ & Stiffening pattern & Unidirectional & $90^{\circ}$ cross & $45^{\circ}$ angle \\
$C$ & Coating layers & No & 1 layer & 2 layers \\
$D$ & Transfer temperature & $80^{\circ} \mathrm{C}$ & $100^{\circ} \mathrm{C}$ & $120^{\circ} \mathrm{C}$ \\
\hline
\end{tabular}

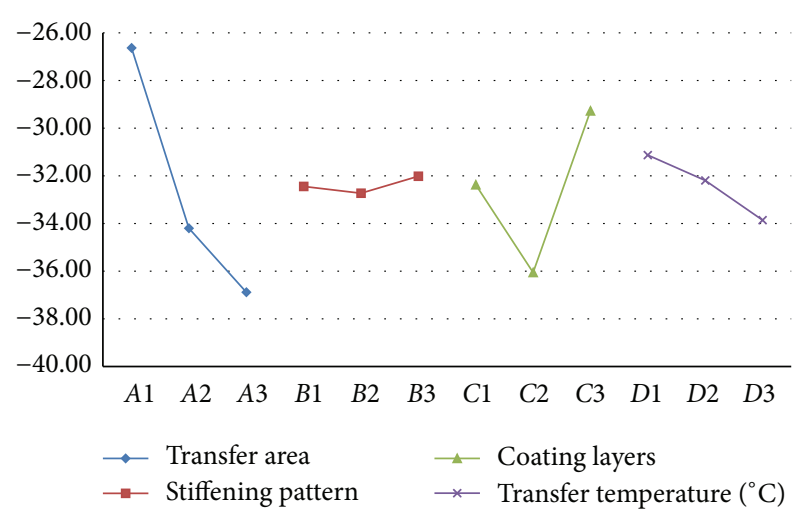

FIGURE 8: Main effect diagram of the high frequency dip difference $(\Delta \mathrm{dB})$.

controllable factors and level numbers. To obtain a minimal difference value, the smaller-the-better characteristic was used to determine the optimal manufacturing parameters as listed in Table 10.

Table 11 presents the cause and effect table, showing the ranking of each experimental factor according to its level of contribution. As shown in Figure 8, the main effect diagram reveals that a factor with a steep slope critically influences the overall experimental results. The crucial factors influencing the high frequency dip difference in the sound pressure curve, in order from highest to lowest level of contribution, were transfer area, coating layers, transfer temperature, and stiffening pattern. By using the ANOVA analysis, significant manufacturing parameters can be easily obtained in this study. The criteria of significant manufacturing parameters are cumulating the contribution ratio to $99.8 \%$. The ANOVA analysis for high frequency dip difference was listed in Table 12 and was plotted as in Figure 9. Specifically, the transfer area has the greatest influence (68.5\%), followed by the coating layers $(25.5 \%)$, transfer temperature $(4.7 \%)$, and stiffening pattern (1.1\%). As a result, to obtain the minimal high frequency dip difference value, transfer area and coating layers are the dominant parameters with contribution at 68.5 and $25.5 \%$, respectively. 
TABLE 10: Smaller-the-better $\mathrm{L}_{9}$ orthogonal array.

\begin{tabular}{lcccccccc}
\hline \multirow{2}{*}{ Number } & \multicolumn{2}{c}{ Factors } & \multicolumn{4}{c}{$\Delta$ dB values } \\
& $A$ & $B$ & $C$ & $D$ & $Y_{1}$ & $Y_{2}$ & $Y_{3}$ \\
\hline 1 & $1 / 2$ & Unidirectional & No & 80 & 2.62 & 2.67 & 2.66 \\
2 & $1 / 2$ & $90^{\circ}$ cross & 1 layer & 100 & 3.19 & 3.15 & 3.11 & -8.4652 \\
3 & $1 / 2$ & $45^{\circ}$ angle & 2 layers & 120 & 2.59 & 2.5 & 2.62 & -8.2004 \\
4 & $3 / 4$ & Unidirectional & 1 layer & 120 & 4.39 & 4.42 & 4.51 & -12.948 \\
5 & $3 / 4$ & $90^{\circ}$ cross & 2 layers & 80 & 3.21 & 3.19 & 3.14 & -10.0489 \\
6 & $3 / 4$ & $45^{\circ}$ angle & No & 100 & 3.61 & 3.66 & 3.62 & -11.1983 \\
7 & $1 / 1$ & Unidirectional & 2 layers & 100 & 3.56 & 3.53 & 3.59 & -11.0292 \\
8 & $1 / 1$ & $90^{\circ}$ cross & No & 120 & 4.31 & 4.37 & 4.28 & -12.7100 \\
9 & $1 / 1$ & $45^{\circ}$ angle & 1 layer & 80 & 4.27 & 4.26 & 4.29 \\
\hline
\end{tabular}

TABLE 11: Cause and effect table of the high frequency dip difference $(\Delta \mathrm{dB})$.

\begin{tabular}{lcccc}
\hline \multirow{2}{*}{ Level } & \multicolumn{4}{c}{ Factors } \\
& $A$ & $B$ & $C$ & $D$ \\
\hline Level 1 & -26.6323 & -32.4426 & -32.3735 & -31.6555 \\
Level 2 & -34.1954 & -32.7256 & -36.0563 & -32.1942 \\
Level 3 & -36.8806 & -32.0140 & -29.2785 & -33.8586 \\
Influence & 10.2483 & 0.2829 & 6.7778 & 2.2031 \\
quantity & 1 & 4 & 2 & 3 \\
Ranking & 1 & & & \\
\hline
\end{tabular}

TABLE 12: Degree of influence of each factor in terms of percentages for the high frequency dip difference $(\Delta \mathrm{dB})$.

\begin{tabular}{cccccc}
\hline & Factors & $S_{k}$ & $V$ & $\begin{array}{c}\text { Influence } \\
\text { percentage }\end{array}$ & $\begin{array}{c}\text { Progressive } \\
\text { percentage }\end{array}$ \\
\hline$A$ & Transfer area & 18.8267 & 9.4133 & $68.5 \%$ & $68.5 \%$ \\
$C$ & Coating layers & 7.6756 & 3.8378 & $25.5 \%$ & $94.0 \%$ \\
$D$ & $\begin{array}{c}\text { Transfer } \\
\text { temperature }\end{array}$ & 0.8794 & 0.4397 & $4.7 \%$ & $98.7 \%$ \\
& $\begin{array}{c}\text { Stiffening } \\
\text { pattern }\end{array}$ & 0.0138 & 0.0069 & $1.1 \%$ & $99.8 \%$ \\
\hline
\end{tabular}

As the optimal manufacturing parameters are not included in the $\mathrm{L}_{9}$ orthogonal array, the optimal manufacturing parameters to attain a stiffened speaker diaphragm with minimal high frequency dip difference value was determined by selecting the maximum points from the main effect diagram of Figure 8. As a result, the optimal parameter combination obtained using the Taguchi method was $1 / 2$ transfer area, $45^{\circ}$ angle ply stiffening pattern, 2 coating layers, and $80^{\circ} \mathrm{C}$ HMA transfer temperature. The $45^{\circ}$ angle ply stiffening pattern has the highest coating area on the PEN surface and leads to a better stiffness. Furthermore, only half area of the diaphragm was coated with CNTs/epoxy composite and the weight of the diaphragm was significantly reduced. Therefore, a CNT-based diaphragm was fabricated using the optimal parameter and named as number 10 . Figure 10 compares the sound pressures curve of the speakers produced using two

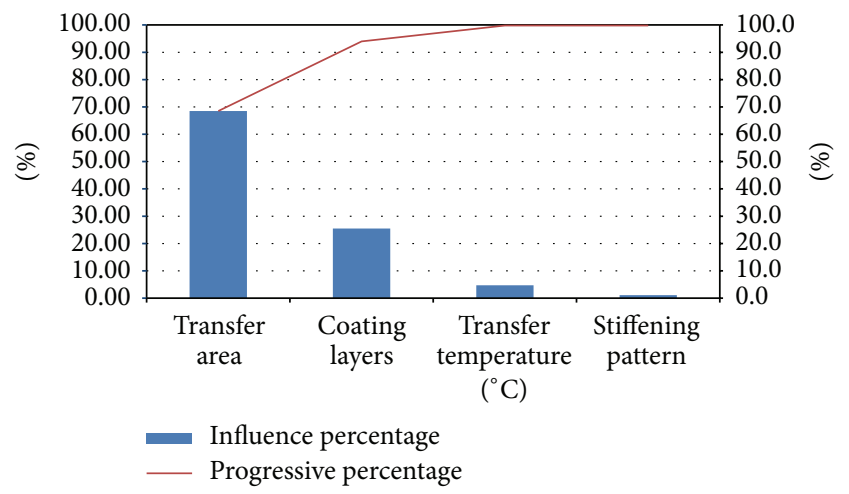

Figure 9: Pareto chart of the high frequency dip difference $(\Delta \mathrm{dB})$.

different CNT-based diaphragms, number 3 and number 10 . The number 3 CNT-based diaphragm exhibits the smallest high frequency dip difference value of the sound pressure curve among the nine diaphragms fabricated form Table 10. The black and red dashed lines and arrows in Figure 10 indicate the high frequency dip difference of number 3 and number 10 diaphragms, respectively. The number 10 CNTbased diaphragm produced a high frequency dip difference $(0.98 \mathrm{~dB})$ smaller than that of number 3 diaphragm $(2.56 \mathrm{~dB})$, improving the high frequency dip difference by $61.72 \%$. Except high frequency region, number 10 CNTbased diaphragm shows a smaller dip difference at high frequency. As shown in Figure 10, the blue dashed line and arrow indicates the dip difference of number 10 CNT-based diaphragm. As a result, at high frequency region, number 10 CNT-based diaphragm shows a small dip difference and a delayed peak frequency as compared to number 3 CNT-based diaphragm.

Actually, the medium-low frequency and high frequency of voices could be both controlled by Young's modulus and stiffness of CNT-based diaphragms and then show the powerful voices. For panel speakers, the CNT-based diaphragms with a high stiffness would result in clear and smooth sound pressure curve at the $20 \mathrm{~Hz} 20 \mathrm{kHz}$. However, the sound properties including the sound pressure curve and the frequency range could be not affected by the strength and the shear stress properties of CNT-based diaphragms. 


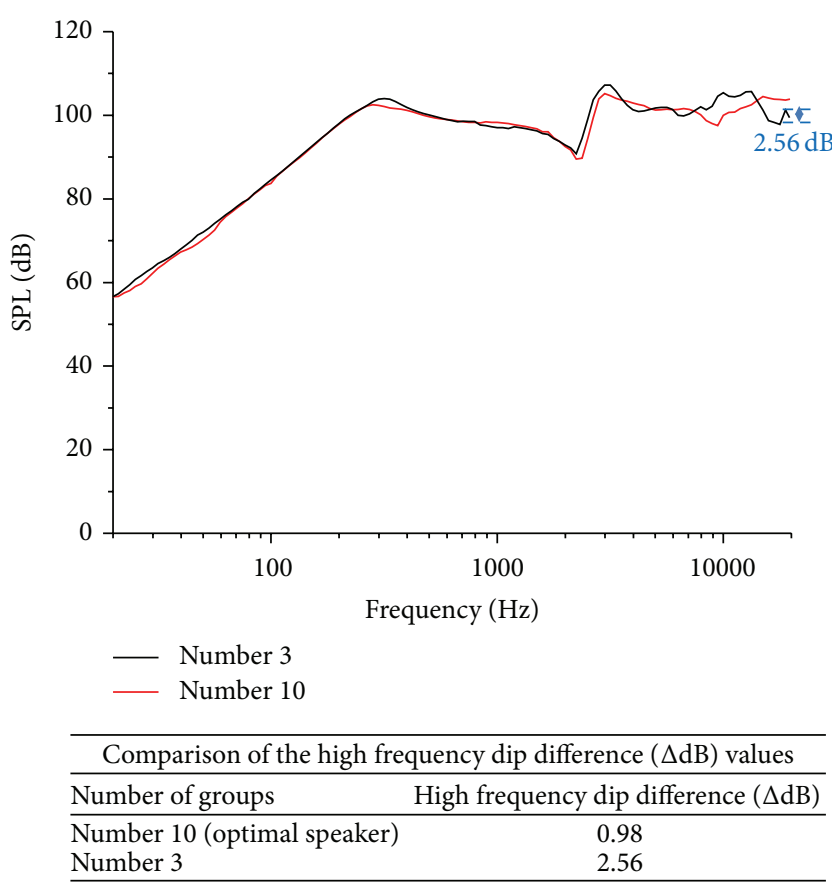

FIGURE 10: Comparison of high frequency dip difference values of the sound pressure curves.

\section{Conclusion}

This study uses laminate plate theory to analyze the thermal transfer printing technology by the assistance of ANSYS. The analytic results from ANSYS method are found to be superior to results from other studies, showing that the proposed hypothesis is valuable. The TTP paper is manufacturing CNT-based diaphragm which has not been delaminated problem in transfer interface for the analytic results from ANSYS method.

Following various experiments and measurements, sound pressure curves were analyzed using the Taguchi method to determine the crucial manufacturing parameters for a TTP technique. The results verified that the CNT-based diaphragm fabricated using the proposed TTP method improved the sound pressure curve smoothness of a panel speaker. Moreover, the Taguchi method was used to effectively identify the optimal manufacturing parameters and the most influential factors. The empirical experiments conducted in this study confirmed that the optimal manufacturing parameters can be used to obtain the minimal high frequency dip difference.

According to the ANOVA analysis, the significant contribution percentage for having the minimal high frequency dip difference was also investigated. For the high frequency dip difference, it was found the transfer area has the greatest influence $(68.5 \%)$, followed by the coating layers $(25.5 \%)$, transfer temperature (4.7\%), and stiffening pattern (1.1\%).

Using the Taguchi quality engineering method, the optimal manufacturing parameters combination for achieving minimum high frequency dip difference composed of a $1 / 2$ transfer area, $45^{\circ}$ angle-shaped stiffening pattern, 2 layers of coating, and a transfer temperature of $80^{\circ} \mathrm{C}$. It was observed that the CNT-based diaphragm and TTP technique improved the smoothness of the sound pressure curve, and the optimal manufacturing parameters enabled fabricating a speaker that produced a high frequency dip difference of $0.98 \mathrm{~dB}$ (improving the difference values by $61.72 \%$ ).

\section{Competing Interests}

The authors declare that there are no competing interests regarding the publication of this paper.

\section{Acknowledgments}

The authors would like to thank the Ministry of Science and Technology in Taiwan for financially support of this research project under Grant no. 102-2221-E-212-006.

\section{References}

[1] M. N. Ozisik, Heat Conduction, John Wiley \& Sons, New York, NY, USA, 1980.

[2] L. L. Shaw, "Thermal residual stresses in plates and coatings composed of multi-layered and functionally graded materials," Composites Part B: Engineering, vol. 29, no. 3, pp. 199-210, 1998.

[3] A. Özel, V. Ucar, A. Mimaroglu, and I. Calli, "Comparison of the thermal stresses developed in diamond and advanced ceramic coating systems under thermal loading," Materials and Design, vol. 21, no. 5, pp. 437-440, 2000.

[4] F. Gardea and D. C. Lagoudas, "Characterization of electrical and thermal properties of carbon nanotube/epoxy composites," Composites Part B: Engineering, vol. 56, pp. 611-620, 2014.

[5] A. Montazeri, J. Javadpour, A. Khavandi, A. Tcharkhtchi, and A. Mohajeri, "Mechanical properties of multi-walled carbon nanotube/epoxy composites," Materials and Design, vol. 31, no. 9, pp. 4202-4208, 2010.

[6] S. M. Park and M. Y. Shon, "Effects of multi-walled carbon nano tubes on corrosion protection of zinc rich epoxy resin coating," Journal of Industrial and Engineering Chemistry, vol. 21, pp. 1258-1264, 2015.

[7] J. M. Wernik and S. A. Meguid, "On the mechanical characterization of carbon nanotube reinforced epoxy adhesives," Materials and Design, vol. 59, pp. 19-32, 2014.

[8] M. M. Shokrieh, A. Daneshvar, and S. Akbari, "Reduction of thermal residual stresses of laminated polymer composites by addition of carbon nanotubes," Materials and Design, vol. 53, pp. 209-216, 2014.

[9] F. M. Lai, "Using ant colony optimization for process variables of thermal transfer printing technology," in Proceedings of the Asian-Pacific Conference on Aerospace Technology and Science, vol. 6, pp. 219-227, 2013.

[10] L. Bian and H. Zhao, "Elastic properties of a single-walled carbon nanotube under a thermal environment," Composite Structures, vol. 121, pp. 337-343, 2015.

[11] K. Z. K. Ahmad, S. H. Ahmad, M. A. Tarawneh, and P. R. Apte, "Evaluation of mechanical properties of epoxy/nanoclay/multiwalled carbon nanotube nanocomposites using taguchi method," Procedia Chemistry, vol. 4, pp. 80-86, 2012.

[12] R. Azadi and Y. Rostamiyan, "Experimental and analytical study of buckling strength of new quaternary hybrid nanocomposite 
using Taguchi method for optimization," Construction and Building Materials, vol. 88, pp. 212-224, 2015.

[13] ANSYS Mechanical APDL Modeling and Meshing Guide, ANSYS Inc, 2011.

[14] ASTM, Astm Standards and Literature References for Composite Materials, Astm International, West Conshohocken, Pa, USA, 2nd edition, 1990.

[15] C. Han and C. T. Sun, "A study of pre-stress effect on static and dynamic contact failure of brittle materials," International Journal of Impact Engineering, vol. 24, no. 6-7, pp. 597-611, 2000. 

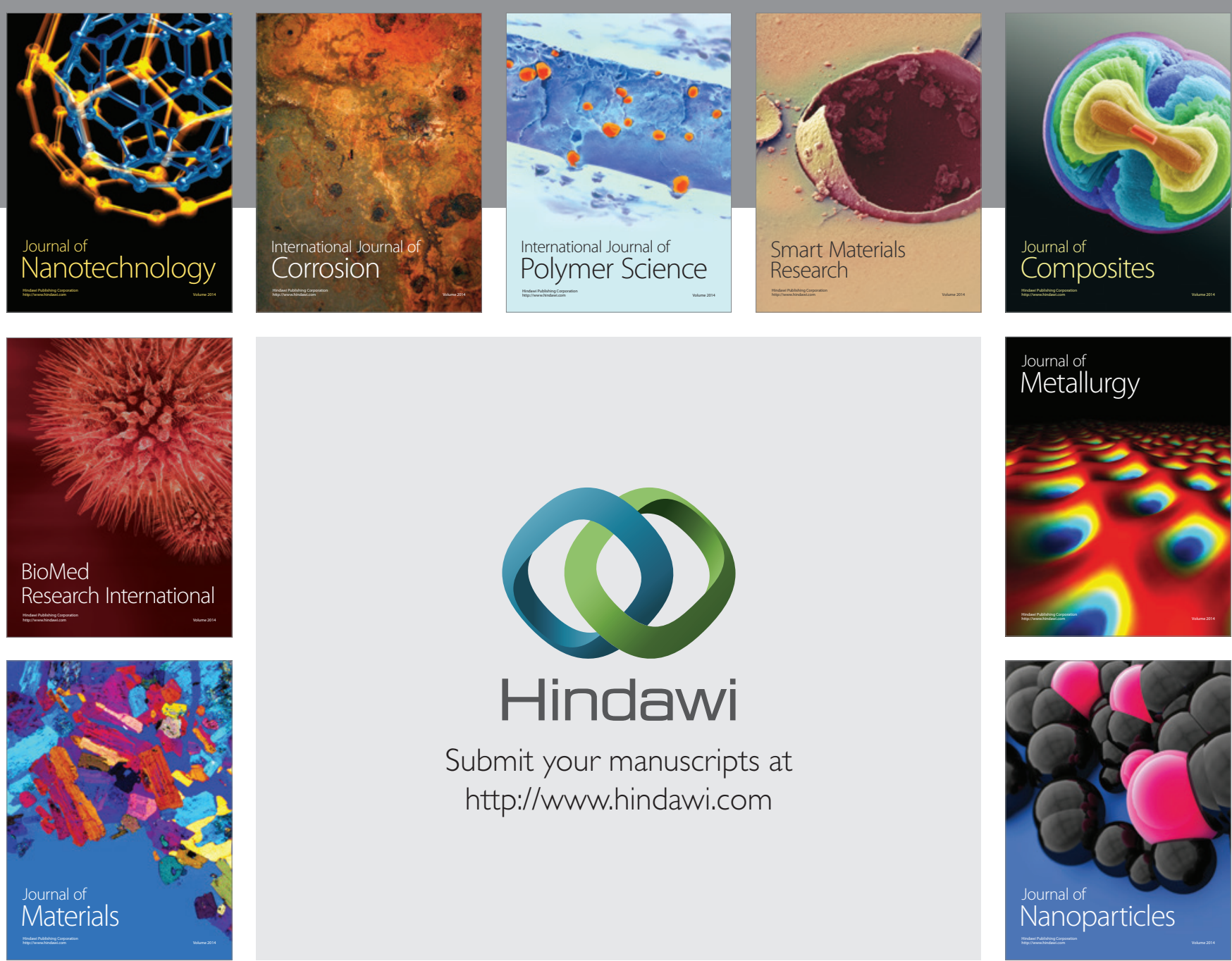

\section{Hindawi}

Submit your manuscripts at

http://www.hindawi.com

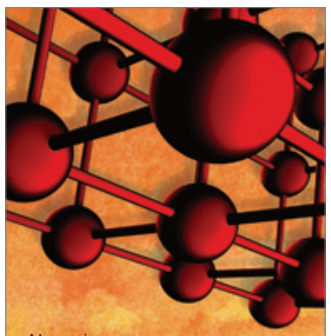

Materials Science and Engineering
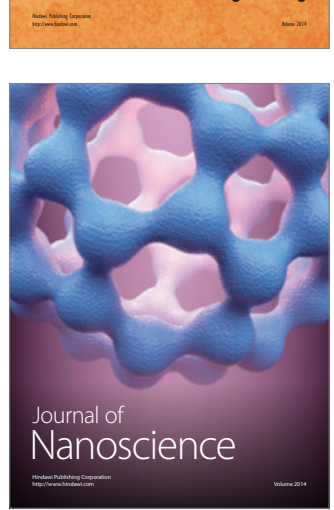
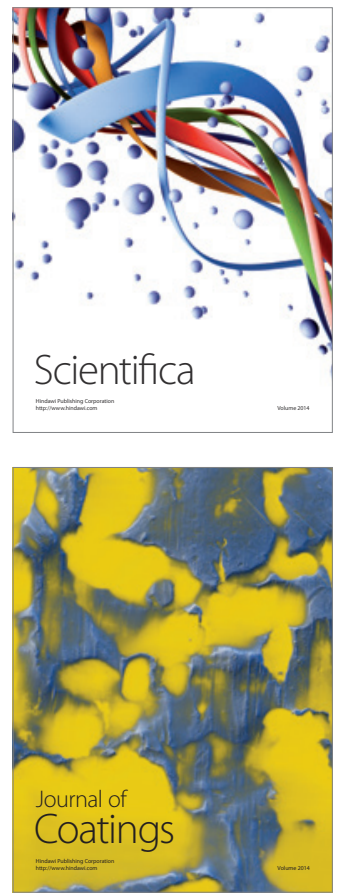
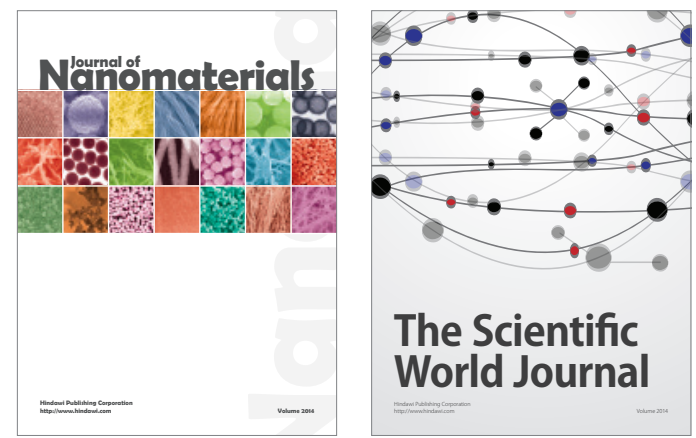

The Scientific World Journal
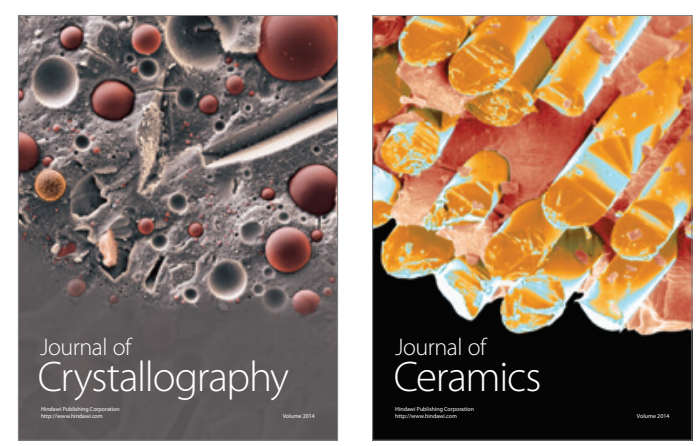
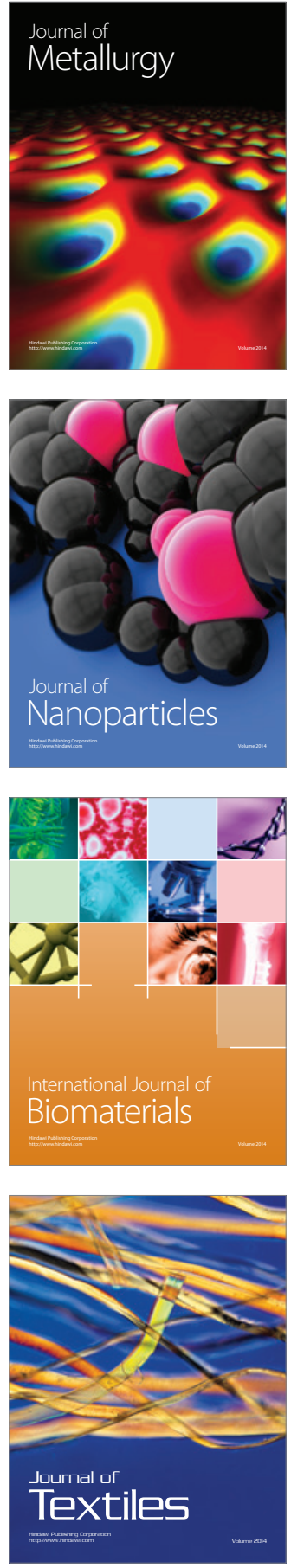